Article

\title{
On the Mechanism of Formation of Conversion Titanium-Containing Coatings
}

\author{
Aleksey Abrashov*(D), Nelya Grigoryan, Tigran Vagramyan and Naum Asnis \\ Department of Innovative Materials and Corrosion Protection, Dmitry Mendeleev University of Chemical \\ Technology of Russia, 125047 Moscow, Russia; ngrigoryan@muctr.ru (N.G.); vagramyan@muctr.ru (T.V.); \\ asnis@muctr.ru (N.A.) \\ * Correspondence: aabrashov@muctr.ru; Tel.: +7-499-9789542
}

Received: 2 March 2020; Accepted: 25 March 2020; Published: 29 March 2020

\begin{abstract}
The present work is devoted to the study of the mechanism of the process of formation of adhesive oxide-titanium coatings on steel, zinc, and aluminum surfaces. For the first time, the following hypothesis has been confirmed experimentally, namely, that nickel, being the first metal to be deposited on a steel substrate, creates active centers on which titanium oxides are formed, because the hydrolysis of hexafluorotitanic acid is adsorbed, which then form a continuous film. The data obtained, regarding the dependence of the coating thickness on the linear rate of the solution flow along the treated surface, indirectly confirm that the formation of insoluble titanium oxides occurs because of the alkalization of the solution adjacent to the surface. It has been established that in the presence of hexavalent molybdenum compounds in the solution as oxidizers, molybdenum is included in the coating in the form of oxides. It has been revealed that in the lower layers of the coating, molybdenum is contained in the form of compounds of molybdenum (V) and (VI), while in the upper layers, it is contained only in the form of the compound of molybdenum (VI).
\end{abstract}

Keywords: corrosion protection; titanium-containing coatings; conversion coatings; hexafluorotitanic acid; passivation of metals

\section{Introduction}

Modern technologies for painting steel surfaces include the preliminary formation of adhesive conversion coatings in order to ensure adhesion and increase the protective ability of the subsequent paint and varnish coating (PVC). Most often, before steel surfaces are painted, they are phosphated; galvanized and aluminum surfaces are chromated, although they are also phosphated when in the fabricated structure [1-3]. The disadvantages of the phosphating and chromating processes are known and have been repeatedly discussed in the literature [4-9].

High energy consumption caused by high operating temperatures (from 70 to $90^{\circ} \mathrm{C}$ ) is a known disadvantage of phosphating processes. In addition, the implementation of modern technologies of crystalline phosphating requires fairly complex equipment. Furthermore, the processes themselves require tight controls, because the properties of the coatings formed are highly dependent on parameters such as the total and free acidity, temperature, concentration of accelerators, etc.

Compounds of hexavalent chromium, which are contained both in chromatizing solutions and in chromate coatings, are rather toxic and carcinogenic.

In recent years, in some types of oxide-titanium adhesion coatings have been proposed as a replacement for the adhesive phosphate and chromate layers under PVC [7,9-17]. Among the advantages of the new coatings are their energy saving production technologies, ease of implementation and operation, and the low toxicity of the solutions used. 
According to the literature to date, the solutions for the formation of these coatings must contain hexafluorotitanic acid; ions of heavy metals, such as nickel, copper, cobalt, silver, and chrome; and an oxidizer, which can be molybdates, hydroxylamine, nitrates, etc. [7,11,12]. Coatings are formed in such solutions after several at $\mathrm{pH} 4-5$ and at room temperature (Figure 1).

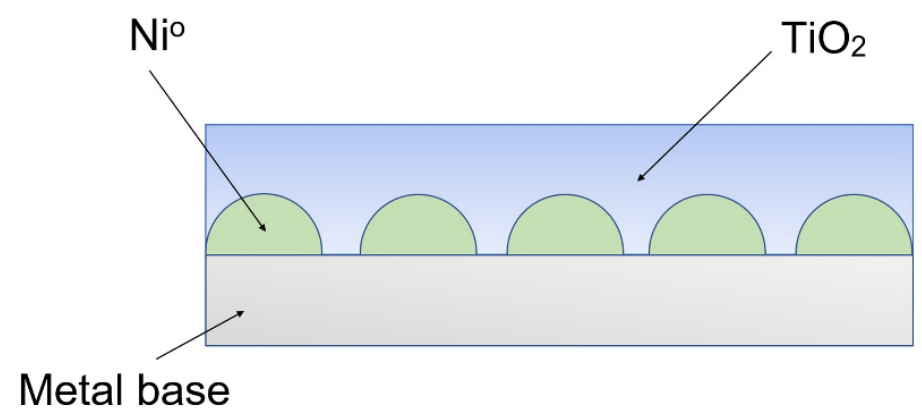

Figure 1. Scheme of formation of coatings.

According to the hypotheses described in the literature, the mechanism of formation of oxide-titanium coatings on steel surfaces at $\mathrm{pH}$ values of 4.0-5.0 for the solution, includes the following reactions [7]:

$$
\begin{gathered}
\mathrm{Fe} \rightarrow \mathrm{Fe}^{2+}+2 \mathrm{e}^{-} \\
2 \mathrm{H}^{+}+2 \mathrm{e}^{-} \rightarrow \mathrm{H}_{2} \\
\mathrm{H}_{2} \mathrm{TiF}_{6}+2 \mathrm{H}_{2} \mathrm{O} \leftrightarrow \mathrm{TiO}_{2}+6 \mathrm{HF} \\
3 \mathrm{Fe}+\mathrm{H}_{2} \mathrm{TiF}_{6}+6 \mathrm{H}_{2} \mathrm{O} \rightarrow \mathrm{TiO}_{2}+\mathrm{FeO}+\mathrm{Fe}_{2} \mathrm{O}_{3}+6 \mathrm{HF}+4 \mathrm{H}_{2} \\
\mathrm{Fe}+2 \mathrm{HF}+\mathrm{H}_{2} \mathrm{O} \rightarrow \mathrm{FeF}_{2} \cdot \mathrm{H}_{2} \mathrm{O}+\mathrm{H}_{2} \uparrow
\end{gathered}
$$

It is assumed that hexafluorotitanic acid is hydrolyzed at $\mathrm{pH} 4-5$ on the surface of the metal to be treated (steel, zinc, or aluminum) with the formation of titanium oxides. These are at first adsorbed on the surface of heavy metals $(\mathrm{Ni}, \mathrm{Cu}, \mathrm{Co}$, and $\mathrm{Cr})$, which are on a steel substrate during contact and then expand, forming a continuous coating.

It is believed that similar processes also occur on a zinc substrate, and the coatings formed in this case consist mainly of oxides of $\mathrm{TiO}_{2}, \mathrm{Ti}_{2} \mathrm{O}_{3}$, and $\mathrm{ZnO}[9,18]$.

The mechanism of formation of titanium-containing coatings on aluminum and its alloys is somewhat different because of the presence of a thin oxide film on their surface. According to the literature data, initially the oxide film dissolves according to the reaction $[15,19]$ :

$$
\mathrm{H}_{2} \mathrm{TiF}_{6}+2 \mathrm{Al}_{2} \mathrm{O}_{3} \rightarrow 4 \mathrm{AlOF}+\mathrm{TiOF}_{2}+\mathrm{H}_{2}
$$

Furthermore, hexafluorotitanic acid oxidizes aluminum as follows:

$$
\begin{gathered}
2 \mathrm{Al}+3 \mathrm{H}_{2} \mathrm{TiF}_{6} \rightarrow 3 \mathrm{H}_{2}+2 \mathrm{Al}^{3+}+3 \mathrm{TiF}_{6}{ }^{2-} \\
2 \mathrm{Al}^{3+}+3 \mathrm{H}_{2} \rightarrow \mathrm{Al}_{2} \mathrm{O}_{3}+6 \mathrm{H}^{+}
\end{gathered}
$$

The oxyfluorides of aluminum and titanium that form as a result of these reactions are also initially adsorbed on the surface of the heavy metal that is deposited during contact, and they then form a continuous coating.

However, no experimental confirmations of the described hypotheses are given in the literature. Understanding the mechanism of formation of coatings is very important for improving existing technological processes and for developing new ones. 
The present work is devoted to the study of the mechanism of the process of formation of adhesive oxide-titanium coatings on steel, zinc, and aluminum surfaces.

\section{Materials and Methods}

The specimens were made of cold-rolled steel A622 grade, 5556 aluminum alloy, and zinc-coated steel.

To prepare the solutions, the chemical reagents of grades "pure", "chemically pure", and distilled water were used.

For an accelerated evaluation of the protective ability of coatings, a drop express method was used for the steel and aluminum substrates using Akimov's reagent, with the solution containing $\mathrm{CuSO}_{4} \cdot 5 \mathrm{H}_{2} \mathrm{O} 82 \mathrm{~g} / \mathrm{L}, \mathrm{NaCl} 33 \mathrm{~g} / \mathrm{L}$, and $13 \mathrm{~mL} / \mathrm{L} 0,1 \mathrm{~N} \mathrm{HCl}$, and for the zinc-coated substrate, the solution contained $\mathrm{Pb}\left(\mathrm{CH}_{3} \mathrm{COO}\right)_{2} 50 \mathrm{~g} / \mathrm{L}$. According to the drop method, the protective ability (PA) of the coating is evaluated in seconds as the color change time of the control area under the drop of the solution, from gray to red-brown (on steel) and to black (on zinc).

The composition of the surface layers was studied using X-ray photoelectron spectroscopy (Omicron, Taunusstein, Germany) (XPS) [20]. Coated samples were fixed in a holder and placed in the pre-evacuation chamber of an OMICRON ESCA+ XPS unit (Omicron). The samples were then transferred to the analyzer chamber, where the pressure was maintained at a level no higher than $8 \times 10^{-10} \mathrm{mbar} . \mathrm{MgK} \alpha$ radiation was used (1253.6 eV; power, $252 \mathrm{~W}$ ). The pass energy of the analyzer was $20 \mathrm{eV}$. To allow for the charge of the samples, the position of the XPS peaks was standardized with respect to the $C$ 1s peak of the hydrocarbon impurities from the atmosphere; the bonding energy $(\mathrm{Eb})$ of the peak was assumed to be $285.0 \mathrm{eV}$. The spectra were decomposed after subtracting the background, determined using the Shirley method [21]. The peak position was determined with an accuracy of $\pm 0.1 \mathrm{eV}$. Component ratios were calculated using integrated intensities under the peaks, while allowing for photoionization cross sections $(\sigma)$ of the respective electron shells [22]. Using the integrated intensity of the peaks and the MultiQuant software (version 7) program [23], the thicknesses of the layers formed on the surface were calculated, with allowance for the mean free path of electrons $(\lambda)$, determined using the formula of Cumpson and Seah [24]. The panoramic spectra were also recorded after argon-ion etching of the coating in different depths. Thus, the composition of the coating at different distances from the substrate was determined. The pressure of the inert gas in the working chamber was maintained at this level, so that the ion energy and the ion current rate, and consequently, the etching rate, were constant. When analyzing the obtained spectra, it was considered that the analyzing beam penetrates the material to the depth of $5 \mathrm{~nm}$, i.e., the resulting spectra correspond to a layer of material $5 \mathrm{~nm}$ thick.

The morphology of the surfaces of the coated specimens was studied using an MPLAPONLEXT 100 lens with the LEXT-OSL 4100 confocal laser microscope (OLYMPUS Corporation, Tokyo, Japan).

The thickness of the coatings was determined by an ellipsometric method using a spectroscopic ellipsometer by Sentech SENreseach (SENTECH Instruments GmbH, Krailling, Germany) 4.0 SER 800 with a high-speed monochromator. The measurements were carried out in the spectral range of wavelengths of 240-1000 nm [25].

The contact angle of the water in contact with the metal plates was determined with the Goniometer LK-1 apparatus (OpenScience, Krasnogorsk, Russia). When working with a goniometer with the camera Levenhuk C310 NG (Levenhuk, Tampa, FL, USA) photographs of the drops were obtained, and then the contact angle was calculated using DropShape software (developed by the Colloid Chemistry Department of the M.V. Lomonosov Moscow State University, Russia, version 3).

\section{Results and Discussion}

The present research was made with a solution that was developed by us previously $[10,15]$ :

$$
\mathrm{H}_{2} \mathrm{TiF}_{6}: 2 \mathrm{~g} / \mathrm{L} ; \mathrm{Ni}^{2+}: 0,08 \mathrm{~g} / \mathrm{L} ;\left(\mathrm{NH}_{4}\right)_{6} \mathrm{Mo}_{7} \mathrm{O}_{24}: 0.1-0.3 \mathrm{~g} / \mathrm{L} ; \mathrm{pH}: 4.0-5.0 ;
$$


It should be noted that in the development of this composition, we studied hydroxylamine, nitrates, and molybdates as oxidizers. The best protective and adhesive coatings were formed in the presence of ammonium molybdate, so it was chosen as a component of the solution.

When the treated specimens were immersed in this solution at a temperature of $18-25{ }^{\circ} \mathrm{C}$, conversion titanium-containing coatings formed on their surfaces. Formation of the coating on steel, galvanized, and aluminum substrates was completed within 30, 60, and $180 \mathrm{~s}$, respectively. Ellipsometric measurements show that the differences in the thicknesses of the coatings formed during this time on steel, zinc-coated steel, and 5556 aluminum alloy were insignificant, at 70, 75, and $68 \mathrm{~nm}$, respectively.

The panoramic X-ray photoelectron spectra revealed the presence of titanium, molybdenum, fluorine, and oxygen compounds, in addition to iron, in these coatings (Figure 2, curve 1), as well as zinc or aluminum, depending on the nature of the substrate.

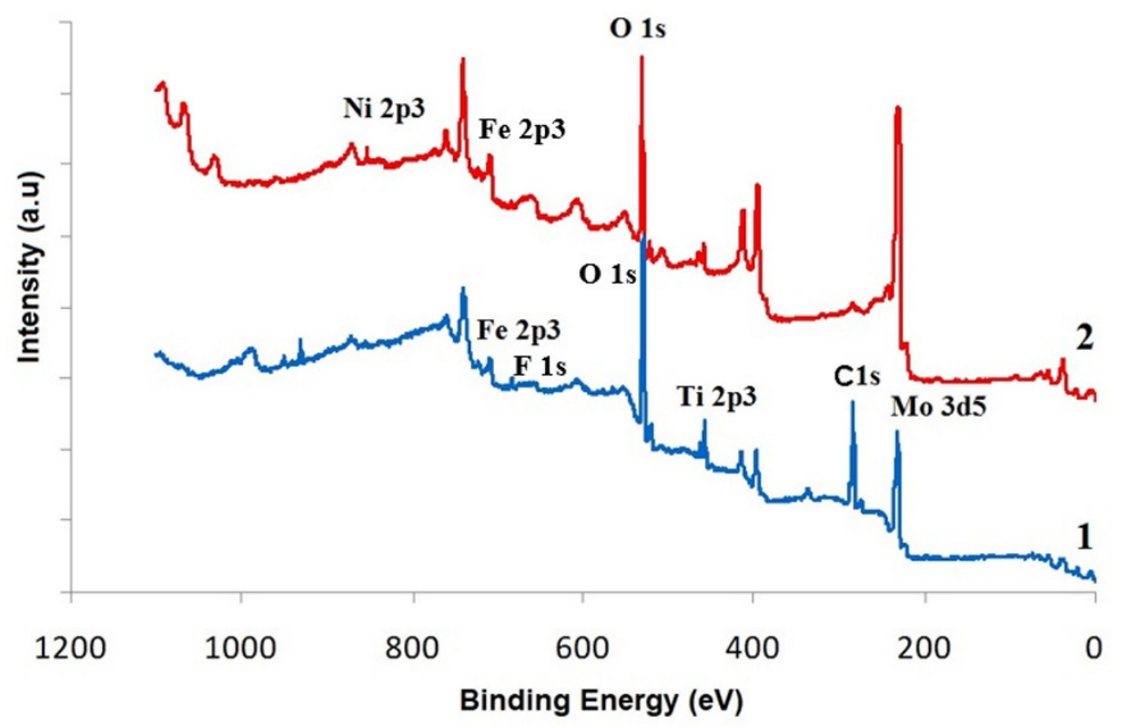

Figure 2. XPS spectra of a specimen with titanium-containing coating on steel prior to etching (1) and after 180 min etching of the coating (2).

The individual spectra of the elements in the coating on a steel substrate allowed us to make assumptions concerning the compounds containing these elements included in the coating. A wide oxygen peak can be interpreted as a mixture of iron, titanium, and molybdenum oxides (Figure 3a). Iron is presented as $\mathrm{FeO}-\mathrm{Fe}_{2} \mathrm{O}_{3}$ oxide $(710.8 \mathrm{eV}$ ) [26] (Figure 3b) and molybdenum is presented as $\mathrm{MoO}_{3}$ oxide (232.7 eV) [27] (Figure 3c). The position of the peak intensity for titanium corresponds to $\mathrm{TiO}_{2}(458.3 \mathrm{eV})[28]$ (Figure 3d).

The individual spectra of these elements in the coating on a zinc substrate indicate that in this case, in addition to the above compounds, a trivalent titanium oxide (456.8 eV) [29] (Figure 4) is present in the coating. Apparently, zinc, being a more electronegative metal, unlike iron, is able to reduce titanium (IV) to titanium (III) under the existing conditions.

Emission peaks of $\mathrm{TiO}_{2}$ and $\mathrm{Al}_{2} \mathrm{O}_{3}$ were found in the spectra of the coatings on aluminum, as was expected.

In the panoramic spectra of coatings on the steel, zinc, and aluminum substrates, the emission peaks of nickel were practically absent. The nickel content in the coating did not exceed $0.2 \%$, which is within the error of the determination. It should be considered that the analyzing beam penetrated the material to a depth of about $5 \mathrm{~nm}$, that is, the spectra presented above correspond to a layer of material with a thickness of about $5 \mathrm{~nm}$. The low intensity of the nickel emission in the panoramic spectra of coatings indicates that nickel was practically absent in the upper layers of the coating. 

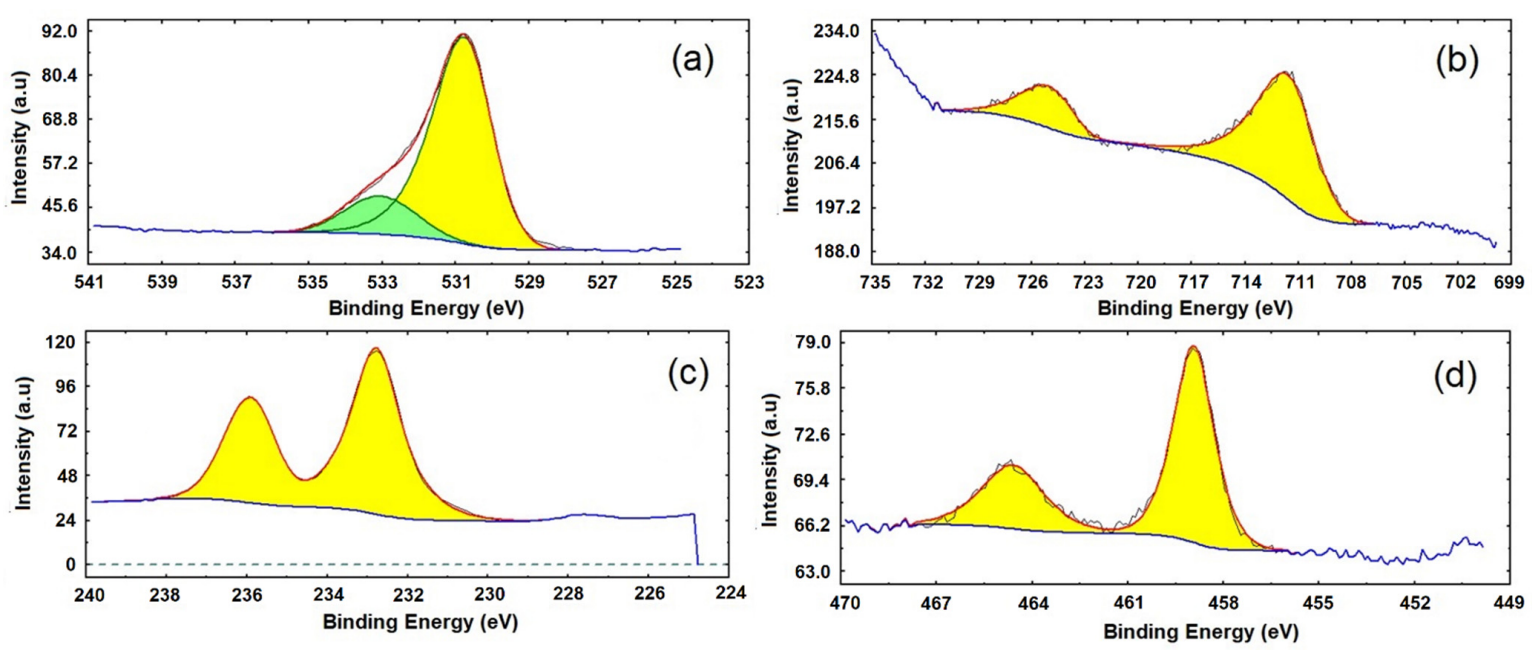

Figure 3. Individual XPS spectra of oxygen (a), iron (b), molybdenum (c), and titanium (d) in the coating on a steel substrate.

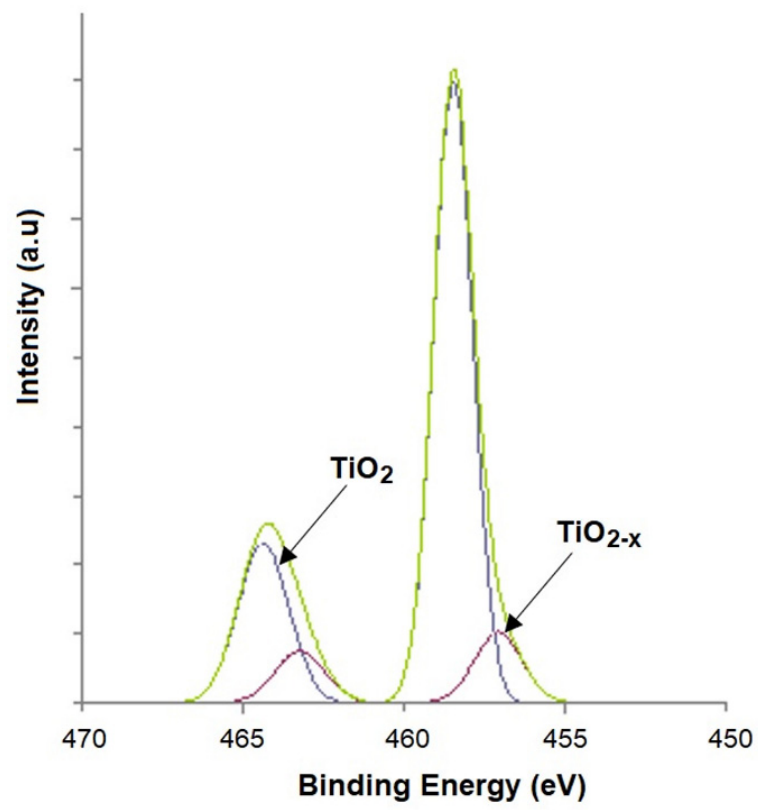

Figure 4. Individual XPS spectra of titanium in a coating on a zinc substrate.

In order to detect nickel in the lower layers of the coating, a layer-by-layer etching of the coatings in the chamber of the X-ray photoelectron spectrometer was carried out, followed by the spectra recordings.

As can be seen from Figure 2 of the panoramic spectrum of the coating on steel substrate after etching the coating for $180 \mathrm{~min}$ (Figure 2, curve 2), the intensity of the emissions of nickel, molybdenum, and iron increased and the intensity of titanium emissions decreased significantly.

The individual spectra of nickel (Figure 5a) indicate that after 20 min of etching of the coating, a peak of metallic nickel $(853.5 \mathrm{eV})$ [30] emission appeared in the spectrum, whose height increased within the interval from 20 to $110 \mathrm{~min}$. At the same time, the emission intensity of $\mathrm{Ni}^{2+}$ decreased practically to zero in the coating spectrum after 50 min of etching. Thus, the metal nickel in the coating was found only adjacent to the substrate layers of the coating.

The individual iron spectra (Figure $5 b$ ) also varied depending on the thickness of the coating: the peak of the emission of metal iron (707.4 eV) [31] appeared in the spectrum after 80 min of etching of the coating, and, as expected, increased as it approached the steel substrate. In addition, the content of iron oxides in the coating also increased as it approached the substrate. 

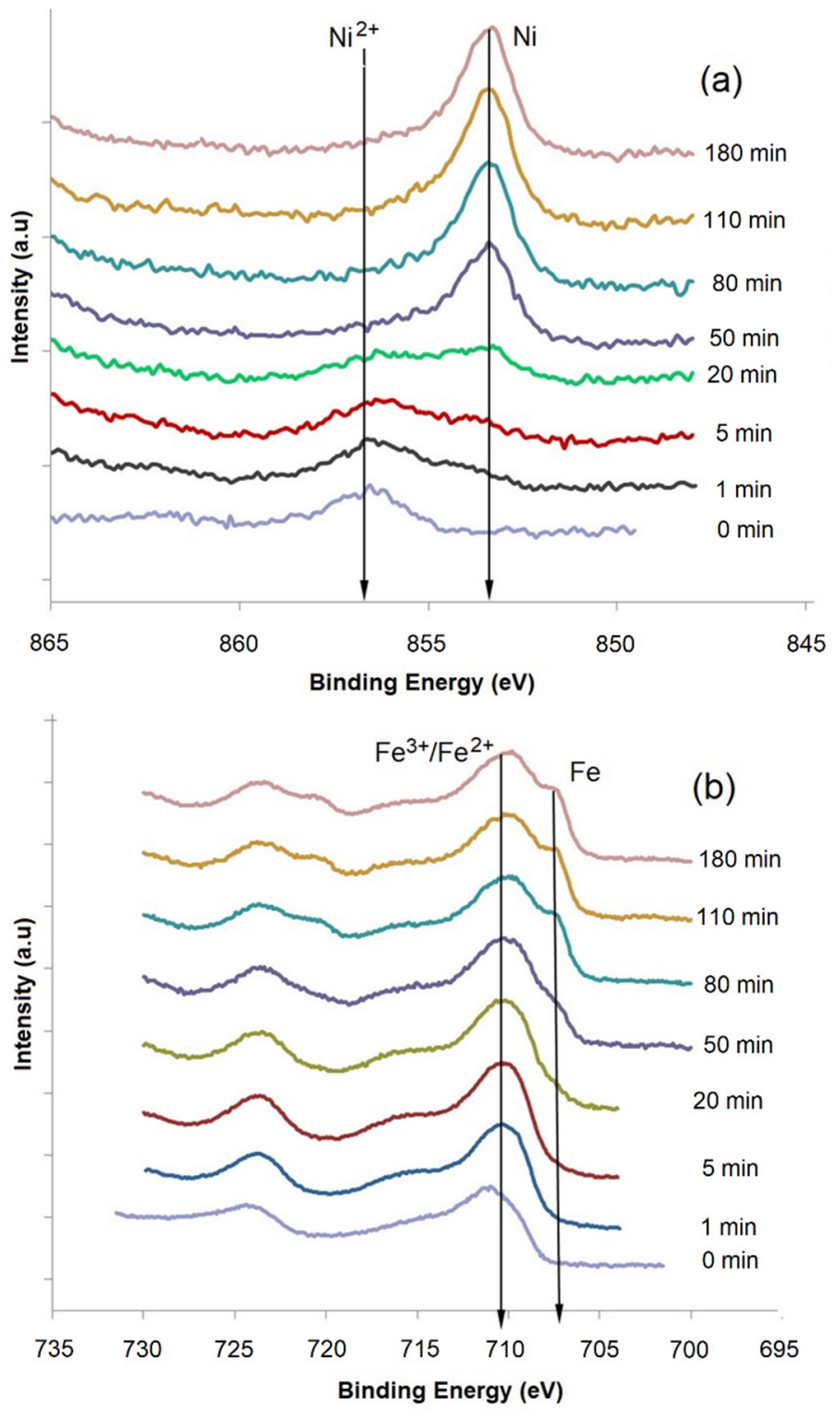

Figure 5. Individual XPS spectra of nickel (a) and iron (b) in the coating on a steel substrate, depending on the duration of etching.

Similar dependencies were obtained for the zinc and aluminum substrates. Metallic nickel was found in the coating layers that lay directly adjacent to both the aluminum and zinc bases.

The results obtained were consistent with the assumption about the contact deposition of nickel at the initial stage of coating formation, as described in the literature. Then, the insoluble titanium oxides, of which the conversion coating mainly consisted, were adsorbed on the deposited metal. It can be assumed that the formation of insoluble titanium compounds due to the displacement of Equation (3) to the right becomes possible because of the alkalization of the boundary layer of the solution, in accordance with Equation (2).

In order to confirm this assumption, the dependence of the thickness of the coating formed during $3 \mathrm{~min}$ on the linear rate of the solution flow on the surface to be treated was studied.

As can be seen from the results in Figure 6, the thickness of the conversion coating increased as the flow rate of the liquid increased from 70 (without mixing) to $140 \mathrm{~nm}$ (at $100 \mathrm{~m} / \mathrm{min}$ ), which is most likely explained by the elimination of diffusion limitations. Reducing the thickness of the coating at high velocities of the solution (more than $100 \mathrm{~m} / \mathrm{min}$ ) is explained by the elimination of the 
alkalization of the solution layer adjacent to the surface, and, consequently, the absence of conditions for the formation of titanium oxides.

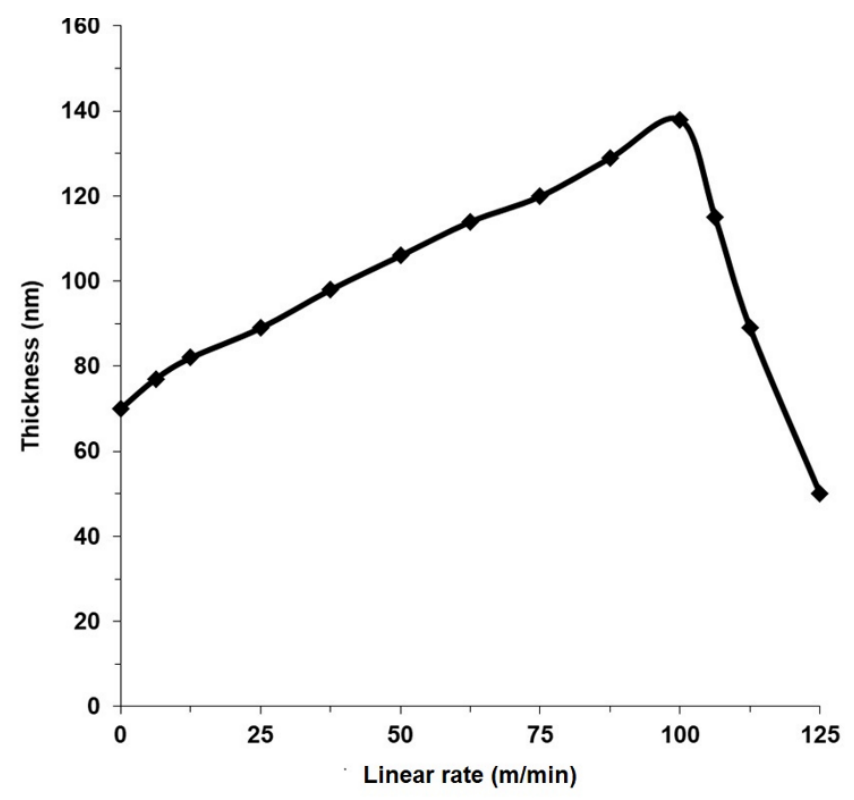

Figure 6. The dependence of the coating thickness on the linear rate of the solution flow along the treated surface.

The high content of molybdenum in the lower layers of the coating (Figure 2, curve 2) can be explained by the partial reduction of hexavalent molybdenum by the substrate metal in order to form the oxides of a lower valency that were included in the coating along with the hexavalent molybdenum oxides. In the upper layers of the coating, molybdenum was presented only in the form of $\mathrm{Mo}^{6+}$ compounds which was confirmed by the individual molybdenum spectrum (Figure 3c).

It was found in the course of the experiments that, with an increase in the duration of coating formation of up to $8 \mathrm{~min}$ or more, an $\mathrm{Mo}^{5+}$ emission peak appeared again in the spectrum of the coating $(231.8 \mathrm{eV})$ [32] (Figure 7). The inclusion of oxides of pentavalent molybdenum in the coating composition led to an increase in the thickness in the process of the deposition duration (Figure 8a). At the same time, the discontinuity of the coatings occurred (Figure 9a,b), which led to a significant decrease in their protective ability (Figure $8 b$ ).

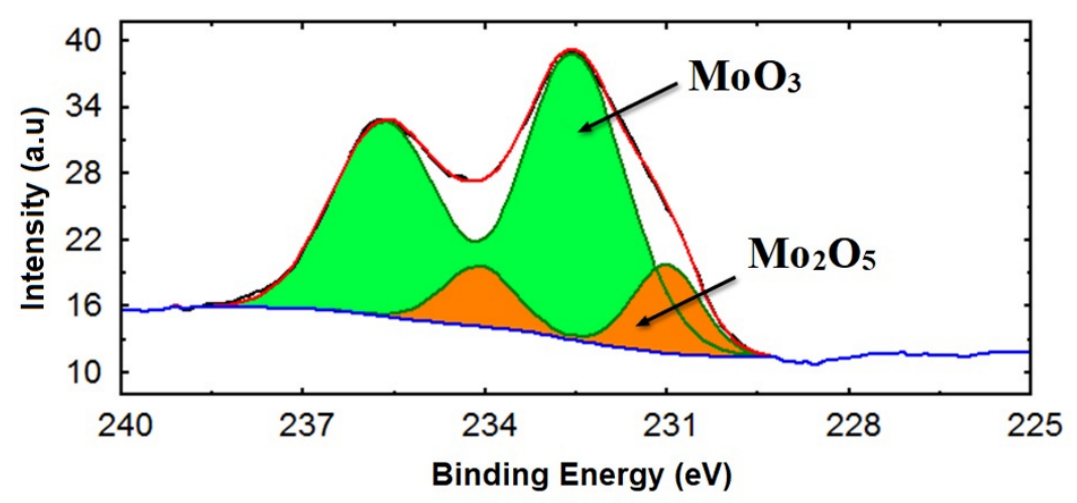

Figure 7. Individual XPS spectra of molybdenum in the coating on a steel substrate (duration of the process $(\tau)=8 \mathrm{~min})$. 

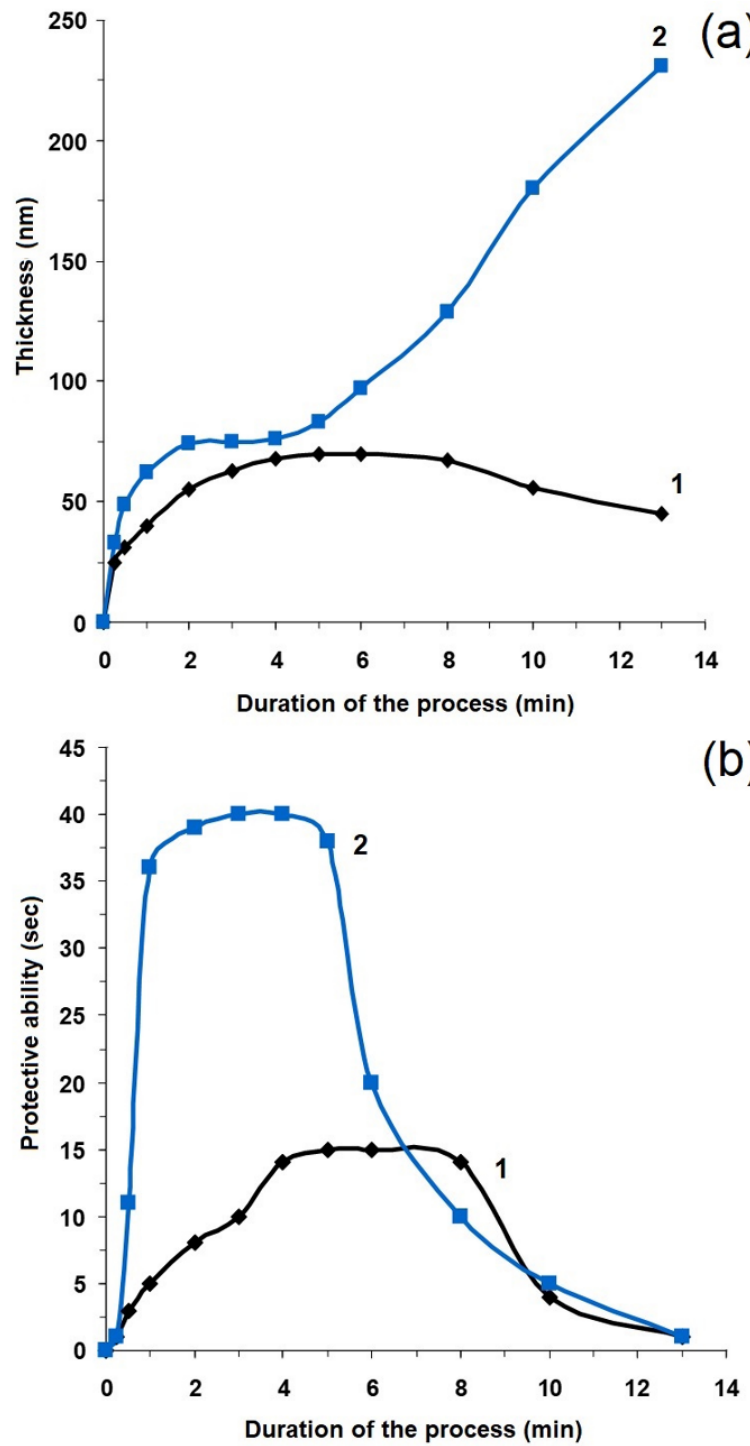

Figure 8. The dependence of the thickness (a) and the protective ability (b) of coatings on the duration of the process $\left(1 . \mathrm{H}_{2} \mathrm{TiF}_{6}: 2 \mathrm{~g} / \mathrm{L} ; \mathrm{Ni}\left(\mathrm{NO}_{3}\right)_{2}: 0.4 \mathrm{~g} / \mathrm{L} ; \mathrm{pH} 4.6-5.0 ; \mathrm{T}: 20{ }^{\circ} \mathrm{C}\right)\left(2 . \mathrm{H}_{2} \mathrm{TiF}_{6}: 2 \mathrm{~g} / \mathrm{L} ; \mathrm{Ni}\left(\mathrm{NO}_{3}\right)_{2}\right.$ : $\left.0.4 \mathrm{~g} / \mathrm{L} ;\left(\mathrm{NH}_{4}\right)_{6} \mathrm{Mo}_{7} \mathrm{O}_{24}: 0.3 \mathrm{~g} / \mathrm{L} \mathrm{pH}: 4.6-5.0 ; \mathrm{T}: 20^{\circ} \mathrm{C}\right)$.

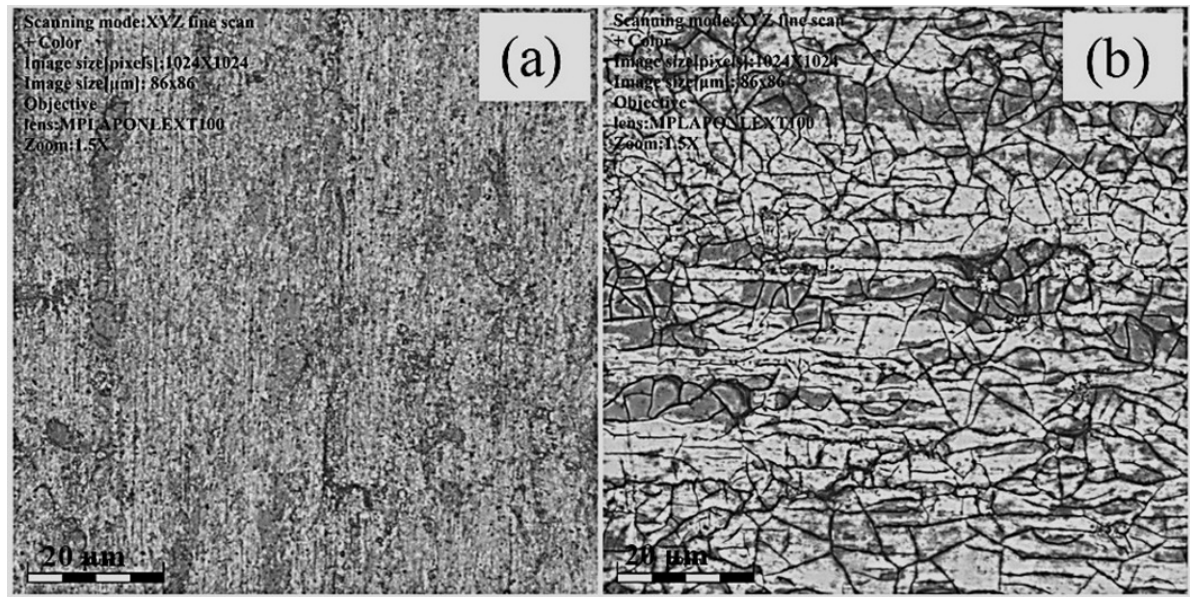

Figure 9. Photographs of the surface of coatings: (a) $\tau=3 \mathrm{~min},(\mathbf{b}) \tau=8 \mathrm{~min}\left(\mathrm{H}_{2} \mathrm{TiF}_{6}: 2 \mathrm{~g} / \mathrm{L} ; \mathrm{Ni}\left(\mathrm{NO}_{3}\right)_{2}\right.$ : $\left.0.4 \mathrm{~g} / \mathrm{L} ;\left(\mathrm{NH}_{4}\right)_{6} \mathrm{Mo}_{7} \mathrm{O}_{24}: 0.3 \mathrm{~g} / \mathrm{L} ; \mathrm{pH}: 4.6-5.0 ; \mathrm{T}: 20{ }^{\circ} \mathrm{C}\right)$. 
The presence of the compounds of pentavalent molybdenum in the coating at an increased duration of its formation is apparently due to the fact that the discontinuity of the coatings associated with its prolonged residence in the solution increases the ability of reduction from $\mathrm{Mo}^{6+}$ to $\mathrm{Mo}^{5+}$ by a metal of substrate, as confirmed by the spectrum shown in Figure 7.

The results show that it is the presence of molybdenum compounds in the coating that provide coatings with their high protective ability. Despite the fact that the thicknesses of the coatings formed during the optimal time ( $3 \mathrm{~min}$ ), in a solution containing no molybdenum compounds and in their presence differ insignificantly (Figure 8a), the protective ability in the second case was much higher (Figure 8b).

In addition, molybdenum-containing coatings are characterized by greater hydrophilicity: the contact angle of these coatings is equal to $29^{\circ}$ compared with the $52^{\circ}$ for coatings that do not contain molybdenum oxides. The hydrophilicity of the adhesive layer under the PVC is a positive factor contributing to the adhesion strength of water-soluble paint-and-varnish materials.

\section{Conclusions}

Thus, the fact of contact precipitation of nickel onto metal substrates, and the further formation of a titanium-containing film, are experimentally confirmed for the first time in the present study. It has also been shown that the coatings consist mainly of titanium oxides and metals of the substrate.

The data obtained regarding the dependence of the coating thickness on the linear rate of the solution flow relative to the surface being treated confirm indirectly that the formation of insoluble titanium oxides occurs due to the alkalization of the solution layer adjacent to the surface.

It has been established that coatings on a steel substrate contain only titanium (IV) oxides, and on zinc and aluminum substrates, coatings contain the oxides of titanium (IV) and titanium (III).

It has also been shown that in the presence of hexavalent molybdenum compounds in the solution as oxidizers, molybdenum is included in the coating in the form of oxides. Findings reveal that in the lower layers of the coating, molybdenum is contained in the form of the compounds of molybdenum $(\mathrm{V})$ and $(\mathrm{VI})$, while in the upper layers, it is contained only in the form of the compounds of molybdenum (VI).

Based on the results of this experimental study, we propose the following mechanism of the formation of coatings:

When the treated metal makes contact with the solution, Reactions (1) and (2) start to proceed, leading to the alkalization of the solution at the surface. As a result, conditions are created for the displacement of the equilibria, as follows:

$$
\begin{gathered}
\mathrm{H}_{2} \mathrm{TiF}_{6}+2 \mathrm{H}_{2} \mathrm{O} \leftrightarrow \mathrm{TiO}_{2}+6 \mathrm{HF} \\
\left(\mathrm{NH}_{4}\right)_{6} \mathrm{Mo}_{7} \mathrm{O}_{24}+6 \mathrm{HF} \leftrightarrow 7 \mathrm{MoO}_{3}+6 \mathrm{NH}_{4} \mathrm{~F}+3 \mathrm{H}_{2} \mathrm{O}
\end{gathered}
$$

towards the formation of insoluble oxides, which are first adsorbed on the surface of the heavy metal $(\mathrm{Ni})$ deposited on the treated substrate by contact reduction, and further expand, forming a continuous coating.

Author Contributions: Conceptualization, N.G.; methodology, N.A.; validation, T.V., and N.G..; investigation, A.A.; resources, T.V. and A.A.; writing-original draft preparation), N.G. and A.A.; writing-review and editing), N.G., A.A., and N.A. All authors have read and agreed to the published version of the manuscript.

Funding: The reported study was supported by the RFBR grant, according to research project no. 18-33-00440.

Acknowledgments: Our special thanks to A. N. Frumkin Institute of Physical Chemistry and Electrochemistry Russian Academy of Sciences (IPCE RAS) for assisting in obtaining XPS spectra images.

Conflicts of Interest: The authors declare no conflict of interest. 


\section{References}

1. Grigoryan, N.S.; Akimova, E.F.; Vagramyan, T.A. Phosphating: Educational book; Globus: Moscow, Russia, 2008 ; p. 144.

2. Sankara, N.T. Surface pretreatment by phosphate conversion coatings-A review. Rev. Adv. Mater. Sci. 2005, 9, 134-152.

3. Mazurova, D.V.; Grigoryan, N.S.; Abrashov, A.A.; Vagramyan, T.A.; Kharlamov, V.I.; Akimova, E.F. Simultaneous phosphatizing of steel, galvanized steel, and aluminium. Prot. Met. Phys. Chem. Surf. 2009, 45, 838-842. [CrossRef]

4. Vakili, H.; Ramezanzadeh, B.; Amini, R. The corrosion performance and adhesion properties of the epoxy coating applied on the steel substrates treated by cerium-based conversion coatings. Corros. Sci. 2015, 94, 466-475. [CrossRef]

5. Kerstnera, E.K.; Kunsta, S.R.; Beltramia, L.V.R.; Vega, M.R.O. Anticorrosive performance of commercial nanoceramic coatings on AISI 1010 steel. Mater. Res. 2014, 17, 1497-1506. [CrossRef]

6. Abrashov, A.A.; Grigoryan, N.S.; Vagramyan, T.A.; Meshalkin, V.P.; Kotel'nikova, A.V.; Gribanova, A.A. Protective adhesive zirconium oxide coatings. Prot. Met. Phys. Chem. Surf. 2016, 52, 1170-1174. [CrossRef]

7. Milosev, I.; Frankel, G.S. Review-Conversion coatings based on zirconium and/or titanium. J. Electrochem. Soc. 2018, 165, C127-C144. [CrossRef]

8. Abrashov, A.A.; Grigoryan, N.S.; Vagramyan, T.A.; Kostyuk, A.G.; Vasilenko, O.A. Nano-adhesion underlayers for painting based on titanium or zirconium oxides. Galvanotekh. Obr. Pov. 2019, 27, 45-51.

9. Abrashov, A.A.; Grigoryan, N.S.; Volkova, A.E.; YArovaya, O.V.; Vagramyan, T.A. Protective titanium oxide nanocoatings on zinc-plated steel. Galvanotekh. Obr. Pov. 2016, 24, 28-34.

10. Abrashov, A.A.; Grigoryan, N.S.; Vagramyan, T.A.; Kolesnikov, A.V. Protective ceramic titanium-oxide nanocoatings. Glass Ceram. 2015, 71, 392-395. [CrossRef]

11. Mohammadloo, H.E.; Sarabi, A.A. Titanium composite conversion coating formation on CRS in the presence of Mo and Ni ions: electrochemical and microstructure characterizations. Appl. Surf. Sci. 2016, 387, 252-259. [CrossRef]

12. Mohammadloo, H.E.; Sarabi, A.A. Titanium-phytic acid nano structured conversion coating formation on CRS substrate. Prog. Org. Coat. 2016, 101, 391-399. [CrossRef]

13. Tsai, Y.-T.; Hou, K.-H.; Bai, C.-Y.; Lee, J.-L.; Ger, M.-D. The influence on immersion time of titanium conversion coatings on electrogalvanized steel. Thin Solid Film. 2010, 518, 7541-7544. [CrossRef]

14. Zuo, X.; Li, W.; Mu, S.; Du, J. Investigation of composition and structure for a novel Ti-Zr chemical conversion coating on 6063 aluminum alloy. Prog. Org. Coat. 2015, 87, 61-68. [CrossRef]

15. Abrashov, A.A.; Grigoryan, N.S.; Vagramyan, T.A.; Zhilenko, D.Y. Ti-taniferous protective coatings on aluminum alloys. Non-ferrous Met. 2016, 11, 33-37.

16. Zhang, C.; Ji, Y.; Zhong, X.; Wu, X. Preparation of a self-developed chrome-free colored coating based on a titanium conversion coating on $6063 \mathrm{Al}$ alloy. RSC Adv. 2016, 6, 62045-62051. [CrossRef]

17. Abrashov, A.A.; Grigoryan, N.S.; Vagramyan, T.A.; Kostyuk, A.G.; Asnis, N.A. Adhesion conversion coatings on iron and non-ferrous metals containing titanium used as substrate for painting. Galvanotekh. Obr. Pov. 2018, 26, 44-49.

18. Guan, Y.; Liu, J.; Yan, C. Novel Ti/Zr based non-chromium chemical conversion coating for the corrosion protection of electrogalvanized steel. Int. J. Electrochem. Sci. 2011, 6, 4853-4867.

19. Faith, G. Chromium-Free Conversion Coating of Aluminium-Copper Alloys. Ph.D. Thesis, University of Manchester, Manchester, UK, February 2010.

20. Woicik, J.C. Hard X-ray Photoelectron Spectroscopy (HAXPES); Springer International Publishing: Cham, Switzerland, 2016; p. 571.

21. Shirley, D.A. High-resolution X-ray photoemission spectrum of the valence bands of gold. Phys. Rev. 1972, 5, 4709-4713. [CrossRef]

22. Scofield, H.; Hartree-Slater, J. Subshell photoionization cross-sections at 1254 and 1487 eV. Electron Spectrosc. Relat. Phenom. 1976, 8, 129-137. [CrossRef]

23. Mohai, M. XPS MultiQuant: multimodel XPS quantification software. Surf. Interface Anal. 2004, 36, 828-832. [CrossRef] 
24. Cumpson, P.J.; Seah, M.P. Elastic scattering corrections in AES and XPS. II. Estimating attenuation lengths and conditions required for their valid use in Overlayer/Substrate experiments. Surf. Interface Anal. 1997, 25, 430-446. [CrossRef]

25. Laha, P.; Schram, T.; Terry, H. Use of spectroscopic ellipsometry to study Zr/Ti films on Al. Surf. Interface Anal. 2002, 34, 677-680. [CrossRef]

26. Hawn, D.D.; DeKoven, B.M. Deconvolution as a correction for photoelectron inelastic energy losses in the core level XPS spectra of iron oxides. Surf. Interface Anal. 1987, 10, 63-74. [CrossRef]

27. Okomoto, Y.; Imanaka, T.; Teranishi, S. Surface structure of $\mathrm{CoOMoO} \mathrm{Al}_{2} \mathrm{O}_{3}$ catalysts studied by X-ray photoelectron spectroscopy. J. Catal. 1980, 65, 448-460. [CrossRef]

28. Bender, H.; Chen, W.; Portillo, J.; Van den Hove, L. AES and XPS analysis of the interaction of Ti with Si and $\mathrm{SiO} 2$ during RTA. Appl. Surf. Sci. 1989, 38, 37-47. [CrossRef]

29. Gonbeau, D.; Guimon, C.; Pfister-Guillouzo, G.; Levasseur, A. XPS study of thin films of titanium oxysulfides. Surf. Sci. 1991, 254, 81-89. [CrossRef]

30. Ertl, G.; Hierl, R.; Knozinger, H.; Thiele, N.; Urbach, H.P. XPS study of copper aluminate catalysts. Appl. Surf. Sci. 1980, 5, 49-64. [CrossRef]

31. Panzuner, G.; Egert, B. The bonding state of sulfur segregated to $\alpha$-iron surfaces and on iron sulfide surfaces studied by XPS, AES and ELS. Surf. Sci. 1984, 144, 651-664. [CrossRef]

32. Vangelista, S.; Cinquanta, E.; Martella, C.; Alia, M. Towards a uniform and large-scale deposition of $\mathrm{MoS}_{2}$ nanosheets via sulfurization of ultra-thin Mo-based solid films. Nanotechnology 2016, 27, 175703. [CrossRef]

(C) 2020 by the authors. Licensee MDPI, Basel, Switzerland. This article is an open access article distributed under the terms and conditions of the Creative Commons Attribution (CC BY) license (http://creativecommons.org/licenses/by/4.0/). 